\title{
PVA-DNA Cryogel Membranes: Characterization, Swelling, and Transport Studies
}

\author{
Adina Papancea, ${ }^{\dagger,}$ Artur J. M. Valente, ${ }^{*}, \dagger$ Silvia Patachia, ${ }^{\ddagger}$ Maria G. Miguel, ${ }^{\dagger}$ and \\ Björn Lindman ${ }^{\dagger, \S}$ \\ Department of Chemistry, University of Coimbra, 3004-535 Coimbra, Portugal, Department of Chemistry, \\ "Transilvania" University of Brasov, 29 Eroilor Str., 500036 Brasov, Romania, and Physical Chemistry 1, \\ Lund University, P.O. Box 124, SE-221 00 Lund, Sweden
}

Received August 27, 2007. In Final Form: October 19, 2007

\begin{abstract}
Double-stranded (ds) DNA from salmon testes has been incorporated into PVA hydrogels obtained by a technique of repeated freezing and thawing. The cryogels obtained are free of potential toxic species like chemical cross-linkers, and consequently, they can be used in pharmaceutical or medical applications. These cryogels show a good mechanical resistance and a white and opaque appearance caused by a heterogeneous porous structure. Encapsulated DNA molecules can be in a compacted or an extended conformation in the PVA matrix and can be controlled by tailoring the degree of crystallinity of the PVA network; this is supported by fluorescence microscopy and UV and FTIR spectroscopic studies. The two forms of encapsulated DNA were observed for different types of matrixes: an extended one in a more crystalline network and a globular one in a more amorphous one. Different associations of base pairs have also been observed. PVA cryogel crystallinity could be tailored by the cryogel contact with different salt solutions. Cryogel surface (scanning electron microscopy) and bulk morphology (porosimetry), swelling, DNA retention, and delivery kinetics have also been studied. All these investigations clearly show strong interactions between PVA and DNA.
\end{abstract}

\section{Introduction}

Poly(vinyl alcohol) (PVA) is a polymer of great interest because of its many desirable characteristics specifically for various biomedical and pharmaceutical applications. ${ }^{1}$ PVA hydrogels are nontoxic, noncarcinogenic, show bioadhesive characteristics, and are easily processed. ${ }^{2}$ Furthermore, PVA gels exhibit a high degree of swelling in water and a rubbery and elastic nature. Because of all these features PVA is an excellent basis for biomaterials. In fact, PVA is capable of simulating natural tissues and can be readily accepted into the body. ${ }^{3}$ PVA gels have been used for contact lenses, ${ }^{4}$ the lining for artificial organs, ${ }^{5}$ and drug delivery applications. ${ }^{6}$

PVA gels can be prepared by chemical or physical crosslinking; general methods for chemical cross-linking are the use of chemical cross-linkers or the use of electron beam or $\gamma$-radiation, whereas the most common method to produce physical cross-linking in PVA is the so-called "freezing-thawing" process. ${ }^{1}$ The "freezing-thawing" method addresses toxicity issues because it does not require the presence of a cross-linking agent, and consequently, no toxicity agents are leaching out from the gel matrix. Furthermore, these physically cross-linked materials also exhibit higher mechanical strength and elasticity than PVA gels prepared by other methods. ${ }^{7,8}$ These properties

* Corresponding author. Phone: +351 239854459. Fax: +351 239 827703. E-mail: avalente@ci.uc.pt.

¿niversity of Coimbra.

$\doteqdot$ "Transilvania" University of Brasov.

$\S$ Lund University.

(1) Hassan, C. M.; Peppas, N. A. Adv. Polym. Sci. 2000, 153, 37-65.

(2) DeMerlis, C. C.; Schoneker, D. R. Food Chem. Toxicol. 2003, 41, 319326.

(3) Chua, C. K.; Leong, K. F.; Tan, K. H.; Wiria, F. E.; Cheah, C. M. J. Mater. Sci.: Mater. Med. 2004, 15, 1113-1121.

(4) Hyon, S. H.; Cha, W. I.; Ikada, Y.; Kita, M.; Ogura, Y.; Honda, Y. J. Biomater. Sci., Polym. Ed. 1994, 5, 397-406.

(5) Dai, W. S.; Barbari, T. A. Biomaterials 2000, 21, 1363-1371.

(6) Coluccio, M. L.; Ciardelli, G.; Bertoni, F.; Silvestri, D.; Cristallini, C.; Giusti, P.; Barbani, N. Macromol. Biosci. 2006, 6, 403-411.

(7) Hassan, C. M.; Peppas, N. A. Macromolecules 2000, 33, 2472-2479.

(8) Hassan, C. M.; Ward, J. H.; Peppas, N. A. Polymer 2000, 41, 6729-6739. are extremely important for the application of PVA gels in biomedical and pharmaceutical fields.

Among biological polyelectrolytes, DNA has always attracted particular interest, and there are numerous studies of the interactions between DNA and polycations. Positively charged agents interact predominantly by electrostatic interactions with DNA molecules and induce DNA compaction, aggregation, and precipitation. Studies of DNA condensation have been performed with cationic surfactants, ${ }^{9-12}$ liposomes, ${ }^{13-16}$ catanionic vesicles, ${ }^{17-19}$ and other oppositely charged polymer. ${ }^{20,21}$ Theoretical work concerning simulations of DNA/polycation systems has been performed in order to understand interactions between the oppositely charged molecules, in particular compaction and confinement in solution ${ }^{22,23}$ and at interfaces. ${ }^{19,24}$ A systematic

(9) Costa, D.; Hansson, P.; Schneider, P.; Miguel, M. G.; Lindman, B Biomacromolecules 2006, 7, 1090-1095.

(10) Rosa, M.; Hansson, P.; Schneider, S.; Miguel, M. G.; Lindman, B. Biomacromolecules 2005, 6, 2164-2171.

(11) Dias, R.; Mel'nikov, S.; Lindman, B.; Miguel, M. G. Langmuir 2000, 16 9577-9583.

(12) Eskilsson, K.; Leal, C.; Lindman, B.; Miguel, M.; Nylander, T. Langmuir 2001, 17, 1666-1669.

(13) Mel'nikov, S. M.; Mel'nikova, Y. S.; Löfroth, J. J. Phys. Chem. B 1998 102, 9367-9369.

(14) Mel'nikova, Y. S.; Mel'nikov, S. M.; Löfroth, J. Biophys. Chem. 1999 $81,125-141$.

(15) Barreleiro, P. C. A.; Lindman, B. J. Phys. Chem. B 2003, 107, 62086213.

(16) Barreleiro, P. C. A.; May, R. P.; Lindman, B. Faraday Discuss. 2003, 122, 191-201.

(17) Mel'nikov, S. M.; Dias, R.; Mel'nikova, Y. S.; Marques, E. F.; Miguel, M. G.; Lindman, B. FEBS Lett. 1999, 453, 113-118.

(18) Dias, R. S.; Lindman, B.; Miguel, M. G. J. Phys. Chem. B 2002, 106 , $12600-12607$

(19) Dias, R. S.; Pais, A. A. C. C.; Linse, P.; Miguel, M. G.; Lindman, B. J. Phys. Chem. B 2005, 109, 11781-11788.

(20) Köping-Höggård, M.; Mel'nikova, Y. S.; Vårum, K. M.; Lindman, B.; Artursson, P. J. Gene Med. 2003, 5, 130-141.

(21) (a) Kabanov, V. A.; Sergeyev, V. G.; Pyshkina, O. A.; Zinchenko, A. A.; Zezin, A. B.; Joosten, J. G. H.; Yoshikawa, J. Macromolecules 2000, 33, 95879593. (b) Philippova, O. E.; Akitaya, T.; Mullagaliev, I. R.; Khokhlov, A. R. Yoshikawa, K. Macromolecules 2005, 38, 9359-9365.

(22) Miguel, M. G.; Pais, A. A. C. C.; Dias, R. S.; Leal, C.; Rosa, M.; Lindman, B. Colloids Surf., A 2003, 228, 43-55. 
study on these interactions is of general significance from the fact that this is considered a very promising field, due to the promising development of synthetic vectors for applications in gene delivery and transfection. ${ }^{25,26}$

Recently, the interaction between covalently cross-linked DNA and oppositely charged surfactants has been investigated. ${ }^{27-29}$ These covalent DNA gels show possible applications for separation purposes as well as acting as a tool for investigating DNA-cosolute interactions by simply monitoring volume changes.

One possible application of PVA is as a matrix for incorporation of biopolymers, such as deoxyribonucleic acid (DNA). In fact, the synthesis of some PVA-DNA blends has been previously reported. Oster et al. ${ }^{30}$ used PVA-based magnetic beads for rapid and efficient separation of DNA/RNA mixtures, whereas Aoi et al. ${ }^{31}$ reported the compatibility between DNA and PVA by preparing PVA films by the solvent cast method. Recently, PVADNA nanoparticles have been prepared by an ultrahigh-pressure technique. ${ }^{32}$ These PVA-DNA nanoparticles have been used for gene delivery.

In this study, we report the synthesis of PVA-DNA (sodium salt from salmon testes) cryogel membranes by the freeze-thaw technique. As pointed out above, the main advantage of this technique is that no additives (such as cross-linker, initiator, etc.) are used in the synthesis. The relation between the DNA configuration and PVA cryogel crystallinity as well as the factors that determine their changes have been investigated. Desorption of DNA from PVA-DNA gel matrixes shows a non-Fickian behavior that can be related with DNA-DNA and/or DNAPVA interactions. Kinetics show that it will be possible to control the leaching out of DNA, which, coupled with the very good mechanical stability of these gel blends, are promising results for biomedical and pharmaceutical applications.

\section{Experimental Section}

2.1. Materials. Poly(vinyl alcohol) (MW 72000 , degree of polymerization $\sim 1600$, degree of hydrolysis $97.5-99.5 \mathrm{~mol} \%$ ) was supplied from Fluka. Double-stranded (ds) DNA (sodium salt from salmon testes) was purchased from Sigma. Sodium bromide from Riedel and sodium chloride and dodecyltrimethylammonium bromide $\left(\mathrm{C}_{12} \mathrm{TAB}\right)$ from Sigma (pro analysis) were used as received.

2.2. Preparation of PVA-DNA Gel Membranes. A PVA solution of $14 \mathrm{wt} \%$ concentration was prepared by dissolving a certain amount of PVA into distilled water at $80^{\circ} \mathrm{C}$ under continuous stirring for $3 \mathrm{~h}$. Two $1 \%$ (wt/wt of PVA) DNA solutions were then prepared, one in water and the other in $10 \mathrm{mM} \mathrm{NaBr}$ solution, by dissolving ds-DNA in water and sodium bromide aqueous solutions, respectively, under continuous stirring.

PVA and DNA solutions were then mixed for $4 \mathrm{~h}$ (also under continuous stirring). After mixing the solutions, they were cast in

(23) Dias, R. S.; Pais, A. A. C. C.; Miguel, M. G. J. Chem. Phys. 2003, 119, $8150-8157$

(24) Dias, R. S.; Pais, A. A. C. C.; Miguel, M. G.; Lindman, B. Colloids Surf., A 2004, 250, 115-131.

(25) Dias, R. S.; Lindman, B.; Miguel, M. G. J. Phys. Chem. B 2002, 106, $12608-12612$

(26) Dias, R.; Antunes, F.; Miguel, M.; Lindman, S.; Lindman, B. Braz. J. Med. Biol. Res. 2002, 35, 509-522.

(27) Costa, D.; Hanssen, P.; Schneider, S.; Miguel, M. G.; Lindman, B. Biomacromolecules 2006, 7, 1090-1095.

(28) Costa, D.; Santos, S.; Antunes, F. E.; Miguel, M. G.; Lindman, B. ARKIVOC 2006, Part 4, 161-172.

(29) Morán, M. C.; Miguel, M. G.; Lindman, B. Langmuir 2007, 23, 64786481

(30) Oster, J.; Parker, J.; Brassard, L. J. Magn. Magn. Mater. 2001, 225, $145-150$.

(31) Aoi, K.; Takasu, A.; Okada, M. Polymer 2000, 41, 2847-2853.

(32) Kimura, T. T.; Okuno, A.; Miyazaki, K.; Furuzono, T.; Ohya, Y.; Ouchi, T.; Mutsuo, S.; Yoshizawa, H.; Kitamura, Y.; Fujisato, T.; Kishida, A. Mater. Sci. Eng., C 2004, 24, 797-801.
Petri boxes and submitted to freezing for $12 \mathrm{~h}$ at $-20^{\circ} \mathrm{C}$ and, after that, thawed for $12 \mathrm{~h}$ at $+25^{\circ} \mathrm{C}$. The cycles of freezing and thawing were repeated three times. After that, the blend gel membranes show a good mechanical resistance and a white and opaque appearance caused by a heterogeneous structure. ${ }^{33}$

2.3. Gel Membrane Characterization. The obtained cryogel membranes were characterized using different techniques.

The incorporation of DNA into PVA gel membranes was characterized by their infrared spectra using a Perkin-Elmer FTIR spectrometer with ATR device. The FTIR spectra were obtained using gel membranes as they were obtained.

DNA fragments inside PVA gel membrane have been visualized by fluorescence microscopy (FM) with an Olympus BX51M microscope, using gel star dye as a fluorescent probe. Gels were stained with the fluorescent dye gel star for $15 \mathrm{~min}$, and after that, they were washed with distilled water prior to be visualized in FM.

The surface morphologies of PVA-DNA blend membranes have been analyzed by scanning electron microscopy (SEM) with a JEOL model 5310 scanning microscope operating under low vacuum at $15 \mathrm{kV}$. The membranes were submitted to a fast cryogenic treatment by diving gel samples into liquid nitrogen for $10 \mathrm{~s}$, and then they were left in a freeze dryer (Free Zone 4.5-Labconco) for $4 \mathrm{~h}$ before being coated with a gold film.

UV absorption spectra of PVA-DNA gel membranes have been recorded on a double-beam Shimadzu UV-2100 using PVA gel membrane as reference.

The porosity of PVA-DNA samples has been measured by mercury porosimetry (Micromeritics Poresizer 9320), according to the method described in the ref 34 .

2.4. Swelling Degree. Different samples of the same membrane were cut, weighed, and immersed in $\mathrm{NaBr}$ aqueous solutions, at five different concentrations, from $1 \mathrm{mM}$ to $0.1 \mathrm{M}$, and left to reach the swelling equilibrium (15 days). After this time, membranes were removed from $\mathrm{NaBr}$ solution, any drops of solution were wiped off, then the weight of the membrane was measured using an analytical balance (ADA 120LE, $\pm 0.1 \mathrm{mg}$ ). Each experiment was repeated twice.

The swelling degree, $Q_{\mathrm{ss}}$, of gel membranes in $\mathrm{NaBr}$ solution can be calculated from the weight of the membrane (swollen gel) after being in equilibrium with the salt solution $\left(M_{\mathrm{s}}\right)$ and dried-xerogel $\left(M_{\mathrm{x}}\right)$ samples, from $Q_{\mathrm{ss}}=M_{\mathrm{s}} / M_{\mathrm{x}}$. The mass of xerogel samples has been obtained using the weight of the sample after synthesis and taking into account the solid content of the gel. ${ }^{35}$

2.5. DNA Release Kinetics. DNA desorption kinetics were performed by immersing a gel membrane sample (as it was synthesized) in a known volume (normally $50 \mathrm{~mL}$ ) of liquid (water, $0.1 \mathrm{M} \mathrm{NaBr}, 0.1 \mathrm{M} \mathrm{NaCl}$, and $14 \mathrm{mM} \mathrm{C}_{12} \mathrm{TAB}$ ). The samples were maintained at $25^{\circ} \mathrm{C}$ using a thermostatic bath. At defined intervals, aliquots of the supernatant were collected. The amount of DNA release from polymeric matrixes, $C_{\mathrm{dt}}$, to the supernatant was quantified by UV-vis spectrophotometry, by measuring the absorbance at 260 $\mathrm{nm}$ with a Jasco V-530 spectrophotometer, according to the method described elsewhere. ${ }^{36}$

Supernatant solutions were renewed at frequent intervals in order to maintain the concentration of desorbed DNA close to zero.

\section{Results and Discussion}

3.1. Blend Characterization. The incorporation of DNA into the PVA gel matrix, in the presence and in the absence of $\mathrm{NaBr}$, was followed by UV spectroscopy (Figure 1). Both spectra show a broad band in the UV region with a maximum at $280 \mathrm{~nm}$ and followed by a shoulder at around $250 \mathrm{~nm}$. The spectra are very

(33) Patachia, S.; Valente, A. J. M.; Baciu, C. Eur. Polym. J. 2007, 43, 460-

(34) Palacio, L.; Prádanos, P.; Calvo, J. I.; Hernández, A. Thin Solid Films 1999, 348, 22-29.

(35) Baker, J. P.; Stephans, D. R.; Blanch, H. W.; Prausnitz, J. M. Macromolecules 1992, 25, 1955-1958.

(36) Rosa, M.; Dias, R.; Miguel, M. G.; Lindman, B. Biomacromolecules $\mathbf{2 0 0 5}, 6,2164-2172$. 


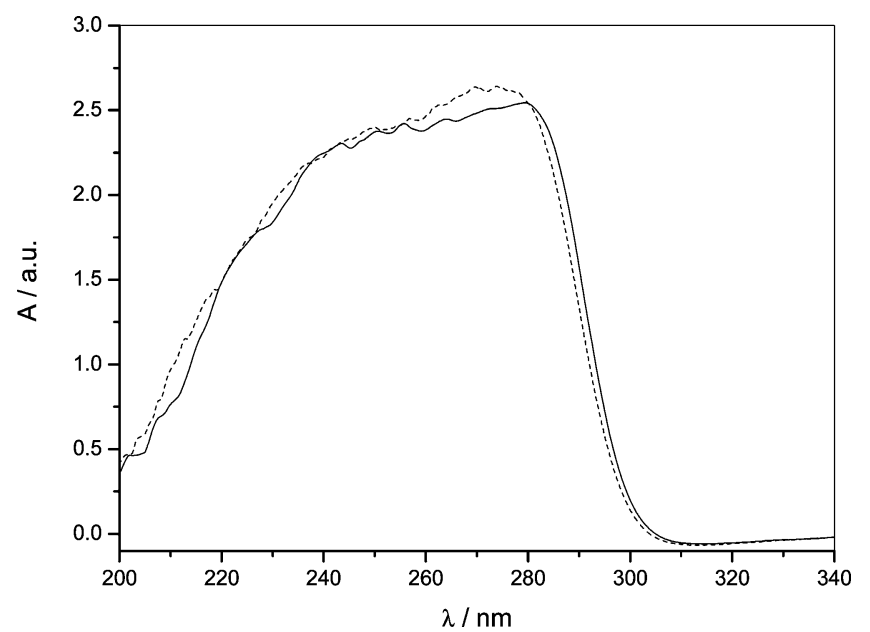

Figure 1. UV spectra of PVA-DNA (solid line) and PVA-DNA$\mathrm{NaBr}$ (dashed line) membranes. The PVA membrane was used as the reference.

similar; however, a small shift of the maximum absorbance to lower wavelength can be seen in the case of the gel containing $\mathrm{NaBr}$ (dashed line in Figure 1). This change is similar to that reported elsewhere ${ }^{36}$ and indicates the presence of ds-DNA in the gel.

Evidence for different conformational states of DNA inside the gel come from FTIR analysis (Figure 2). Figure 2a, curve I shows the characteristic bands of the sample with PVA alone. One band corresponding to hydrogen bonds $(-\mathrm{OH})\left(3283 \mathrm{~cm}^{-1}\right)$ and two bands (at 2924 and $2855 \mathrm{~cm}^{-1}$ ), which can be assigned to $\mathrm{C}-\mathrm{H}$ alkyl stretching vibrations, ${ }^{37}$ are indicated. A very strong band at a frequency of $v=1090 \mathrm{~cm}^{-1}$ is related to the CO stretching band. This vibrational band is attributed to the crystallinity of the PVA, and it is interpreted in terms of the formation of intra- and intermolecular hydrogen bonding among PVA chains, due to strong hydrophilic forces. ${ }^{38}$ The incorporation of DNA in PVA produces an alteration of the vibration modes in the region of $1660-1560 \mathrm{~cm}^{-1}$ (base region). In the PVADNA gels it is possible to observe two strong bands at 1652 and $1560 \mathrm{~cm}^{-1}$. These bands can be assigned to the $\mathrm{C} 2=\mathrm{O} 2$ stretching vibration of cytosine and to a couple of $\mathrm{C} 6=\mathrm{O} 6, \mathrm{C} 5-\mathrm{C} 6$, and $\mathrm{C} 4=\mathrm{C} 5$ stretching vibrations of guanine. ${ }^{39} \mathrm{~A}$ strong vibration mode at $1652 \mathrm{~cm}^{-1}$ can also be seen for both the DNA-containing gels. When the blend DNA-PVA is produced in the presence of $\mathrm{NaBr}$, a further vibration mode at around $1590 \mathrm{~cm}^{-1}$ can be observed. This band can be assigned to the ring vibrations of guanine. ${ }^{40}$

These alterations in the spectra seem to reflect a different base-pairing (or - stacking) pattern between the two different forms of DNA-containing gels.

In order to investigate the state of DNA molecules inside the blend matrix, an FM analysis was carried out. Pure PVA does not show any fluorescent spot; however, bright fluorescent spots can be found in DNA-containing gels. In the case of a PVADNA gel membrane, the DNA molecules are in the extendedcoil formation (Figure 3A). With the addition/incorporation of $\mathrm{NaBr}$, however, the DNA molecules collapsed into a globular conformation (Figure 3B). This can be understood from the effect

(37) Mansur, H. S.; Oréfice, R. L.; Mansur, A. A. P. Polymer 2004, 45, 71937202.

(38) (a) Hennik, W. E.; Nostrum, C. F. Adv. Drug Delivery Rev. 2002, 54, 13-36. (b) Peppas, N. A. Makromol. Chem. 1977, 178, 595-601.

(39) Lindqvist, M.; Gräslund, A. J. Mol. Biol. 2001, 314, 423-432.

(40) Tsuboi, M. Application of infrared spectroscopy to structure studies of nucleic acids. In Applied Spectroscopy Reviews; Brame, E. G. J., Ed.; Dekker: New York, 1969; pp 45-90.
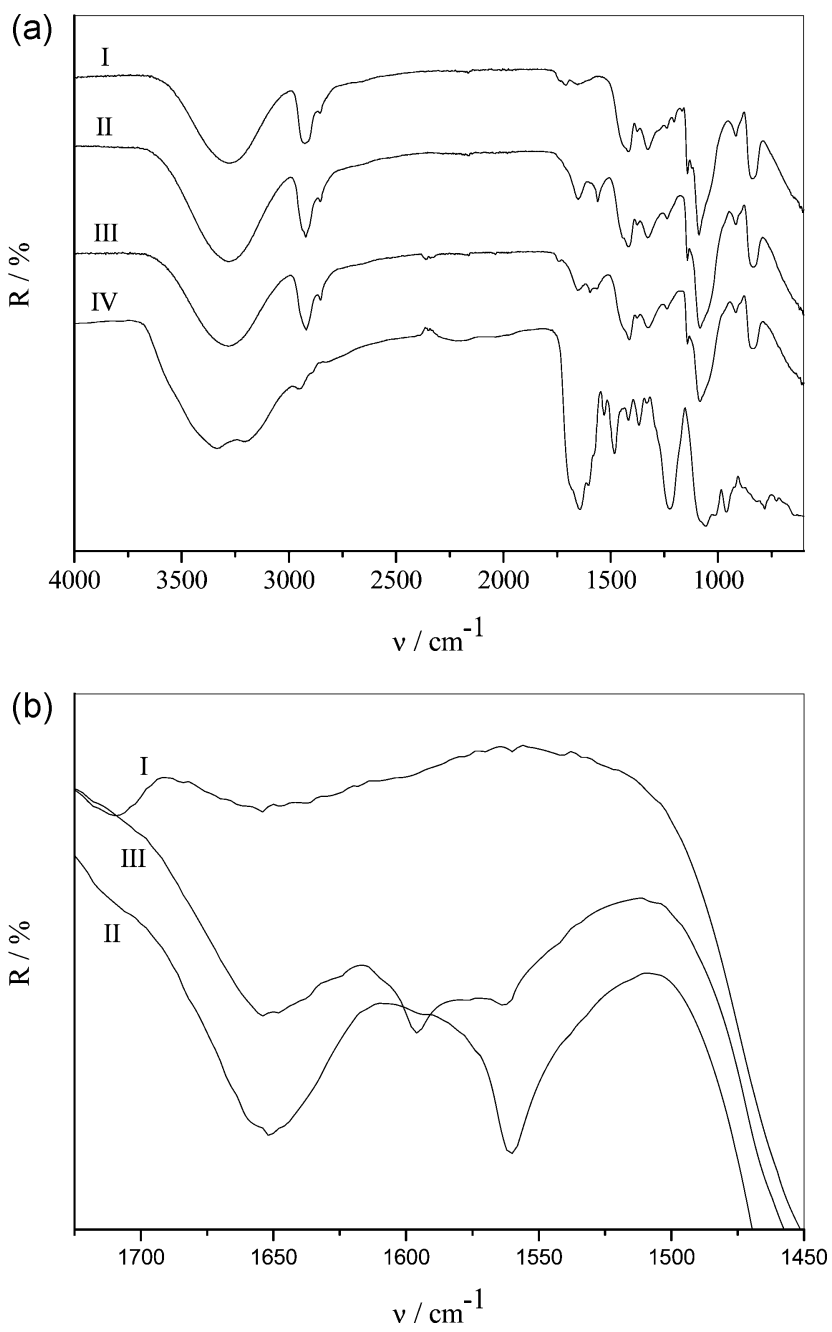

Figure 2. (a) Infrared spectra of PVA (I), PVA-DNA (II), PVADNA $-\mathrm{NaBr}$ (III), and solid DNA sodium salmon testes (IV). (b) Detail of IR spectra: PVA (I), PVA-DNA (II), PVA-DNA- $\mathrm{NaBr}$ (III).

of salt addition as a screener of electrostatic interactions between DNA chains, contributing to a stabilization of a compact DNA structure. It should be noted that the effect of $\mathrm{NaBr}$, on the DNA structure, in the gel membrane, is similar to that found by the addition of an azobenzene trimethylammonium bromide surfactant in DNA aqueous solution in the presence of visible light. ${ }^{41}$ Such a behavior suggests that PVA matrixes can be used for compaction/decompaction of DNA (see transport discussion).

The presence of DNA inside the gel matrixes also affects the surface morphology and bulk properties. Figure 4 shows the SEM micrographs of the different PVA membranes. The PVA membrane shows a very homogeneous porous surface, ${ }^{42}$ with a maximum size of the pores around $1.0-1.5 \mu \mathrm{m}$. In the PVADNA blend membrane (Figure 4b) there is a different surface morphology. A rather compact skeleton separated by holes of diameters of around $50 \mu \mathrm{m}$ can be inferred. However, when the incorporation of DNA is done in the presence of $\mathrm{NaBr}$, the membrane surface is quite similar to that found with PVA alone but with larger pores, some of them with $100 \mu \mathrm{m}$ diameter, and the compaction, seen in Figure $4 \mathrm{~b}$, is lost. The general feature of PVA membranes is maintained in all cases. In no case, is there any evidence of macroscopic phase separation between DNA and PVA. This is in close agreement with data reported by Aoi

(41) Ny, A.-L. M. L.; Lee, C. T., Jr. J. Am. Chem. Soc. 2006, 128, 6400-6408 (42) Wan, Y.; Huang, W.; Wang, Z.; Zhu, X. X. Polymer 2004, 45, 71-77. 


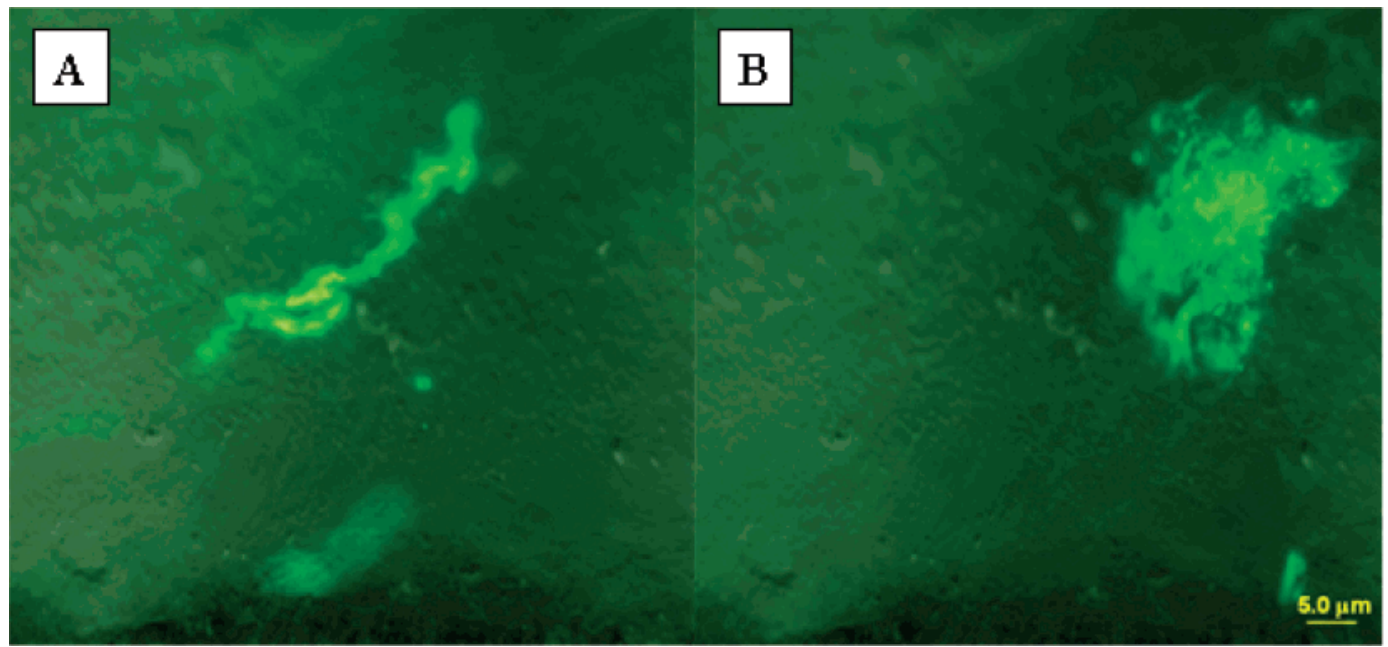

Figure 3. Fluorescent images of PVA-DNA (A) and PVA-DNA-NaBr (B) gel membranes. Fluorescent images are overlapped to a phase contrast micrograph of PVA. Gel star was used as a fluorescent probe.

(a)

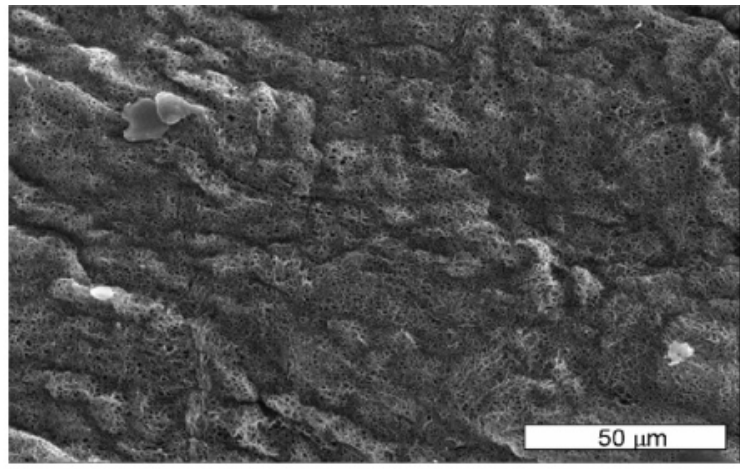

(b)

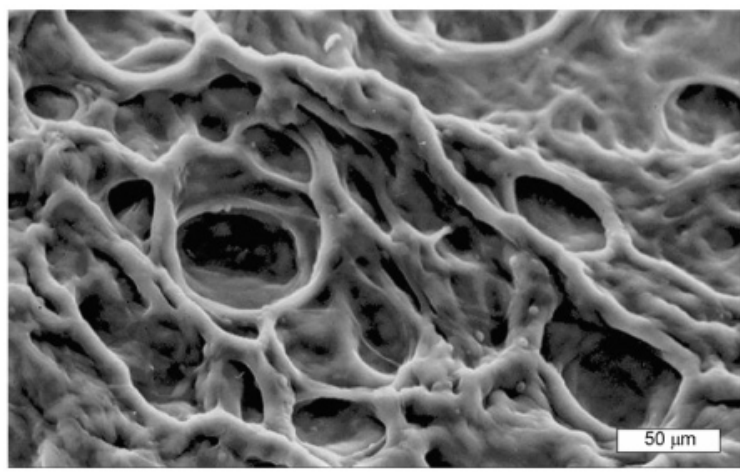

(c)

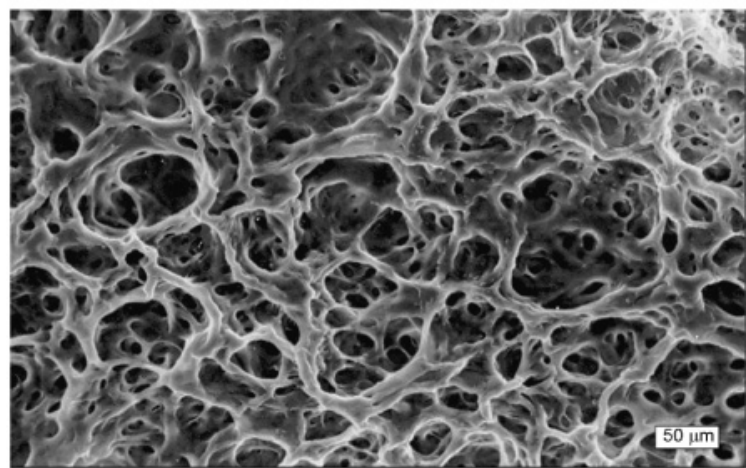

Figure 4. Scanning electron micrographs of (a) PVA $(23 \mathrm{kV}, \times 500)$, (b) PVA-DNA $(25 \mathrm{kV}, \times 350)$, and (c) PVA-DNA-NaBr $(25 \mathrm{kV}$, $\times 200)$ gel membranes.

et al. ${ }^{31}$ where the compatibility (that is, "a microseparated structure with improved properties") is demonstrated by differential scanning calorimetry and dynamical mechanical analysis.
Table 1. Pore Parameters of PVA Gels ${ }^{a}$

\begin{tabular}{lccc}
\hline & $\phi / \%$ & $\emptyset_{\mathrm{av}} / \mu \mathrm{m}$ & $d_{\mathrm{ap}} /\left(\mathrm{g} \mathrm{cm}^{-3}\right)$ \\
\hline PVA & 8.63 & 0.0130 & 1.1689 \\
PVA-DNA & 7.14 & 0.0201 & 1.1701 \\
PVA-DNA-NaBr & 8.01 & 0.0267 & 1.1853
\end{tabular}

${ }^{a} \phi$, porosity; $\emptyset_{\mathrm{av}}$, average pore diameter; $d_{\mathrm{ap}}$, apparent density.

The increase in the pore dimensions in the sequence PVADNA $-\mathrm{NaBr}>$ PVA-DNA $>$ PVA is also confirmed by the porosity measurements (Table 1 ), where the average pore diameter (including the bulk structure) follows the same trend. This is in close agreement with data recently reported concerning DNA gel particles. ${ }^{29}$ However, the increase of pore diameter is not followed by an increase in the pore volume, which is quantified by the porosity.

The PVA-DNA blend membrane shows a decrease in the porosity by about $17 \%$ when compared with PVA gels. This fact gives evidence for the presence of interactions between PVA and DNA. In fact, it has been reported that in the presence of ethanol, which is considered as a solvent homolog of PVA, ${ }^{31}$ there is a conformational change of DNA from the B-form, in which water interacts with the oxygens of ribose and phosphate, to the tighter C-type conformation of parallel DNA threads. ${ }^{43}$ This conformation is in agreement with the red shift found by UV spectroscopy (Figure 1$)^{44}$ and with the stretched DNA structure as seen by FM. Such alterations can explain interactions occurring between DNA and PVA and an accompanying decrease in porosity.

The increase of the skeleton density ( $d_{\text {ap }}$ in Table 1$)$ also indicates that DNA molecules are not separated from those of PVA. They form together a compatible blend and a common skeleton of the gel. Crystallinity of PVA cryogels decreases in the presence of bromide ions. ${ }^{45}$ Consequently, it can be suggested that in more crystalline gels, DNA molecules are forced to extend their molecules generating a semi-interpenetrated network known as a "snake cage" structure. ${ }^{45}$ However, in more amorphous gels, due to the higher mobility of the PVA chains between the crystalline parts, DNA molecules show stronger self-interaction, generating globular structures.

(43) Gray, D. M. Biopolymers 1975, 14, 487-498.

(44) Girod, J. C.; Johnson, W. C., Jr.; Huntington, S. K.; Maestre, M. F. Biochemistry 1973, 12, 5092-5096.

(45) Paţachia, S. Blends based on poly(vinyl alcohol) and the products based on this polymer. In Handbook of Polymer Blends and Composites; Vasile, C., Kulshreshtha, A. K., Eds.; RAPRA Technology Ltd.: England, 2003; Chapter 8, pp 288-365. 


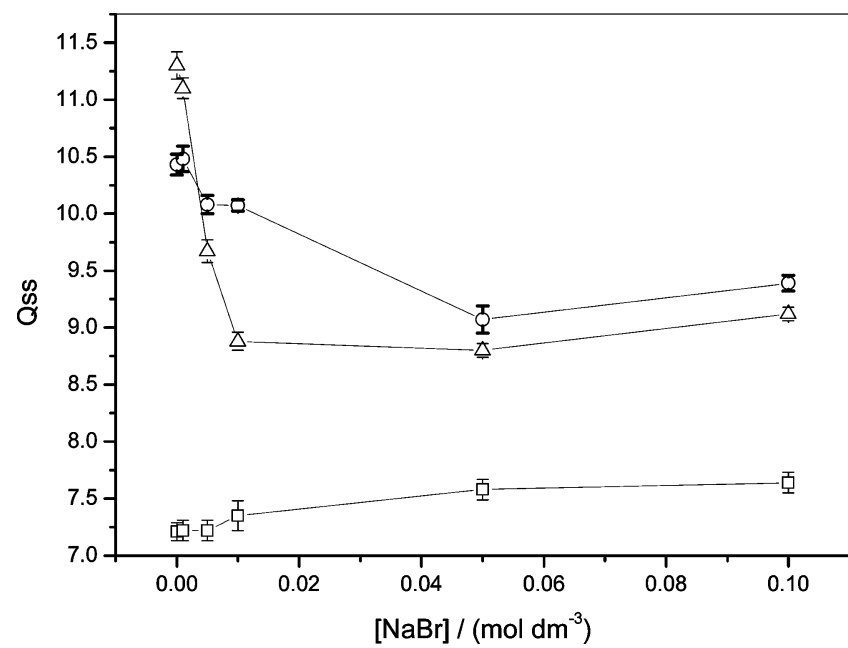

Figure 5. Degree of swelling of $(\square)$ PVA, (O) PVA-DNA, and $(\triangle)$ PVA-DNA- $\mathrm{NaBr}$ membranes in aqueous $\mathrm{NaBr}$ solutions at $25^{\circ} \mathrm{C}$. Solid lines are guides for the eye.

The compaction of DNA molecules in PVA gels containing $\mathrm{NaBr}$ could also explain the higher increase of the skeleton density for this blend (with $1.40 \%$ ) when compared with the very small increase in the case of PVA-DNA gels (with $0.10 \%$ ).

SEM images of PVA, PVA-DNA, and PVA-DNA- $\mathrm{NaBr}$ are in good agreement with the previous discussion on the properties of the gels. In fact, the lower crystallinity of the PVA gel corresponds to thicker pore walls. When the crystallinity of PVA is influenced by the components of the gels (DNA and $\mathrm{DNA}+\mathrm{NaBr}$ ), the thickness of the pore walls will change. As a consequence, the number of pores and their dimensions will also change, suggesting that the dimension of the pores increases and that the number of pores decreases with an increase of PVA crystallinity.

3.2. Swelling Degree. The effect of water and electrolyte $(\mathrm{NaBr})$ on the swelling degree of PVA and cryogel blends was also investigated (Figure 5).

The most important observations that can be made from Figure 5 are (a) the presence of DNA in the membranes increases the swelling of the membranes strongly; (b) electrolyte addition causes a marked deswelling for the DNA-containing membranes but not for the others; (c) for the membranes with PVA alone there is a notable swelling on addition of $\mathrm{NaBr}$; an analogous effect is observed for the PVA-DNA membranes at higher $\mathrm{NaBr}$ concentrations.

The difference between polyelectrolyte membranes and membranes based on nonionic polymer alone as well as the electrolyte-induced deswelling demonstrate the dominance of electrostatic effects: There is osmotic swelling associated with the entropy of the counterions. As electrolyte is added this effect is strongly reduced as the membrane and reservoir counterion concentrations are becoming more equal.

The electrolyte-induced swelling effect is of another nature. This is related to a (weak) association of bromide ions to the polymer matrix due to dispersion interactions; such an association is well-known and depends on the ion polarizability. The mechanism is very important for the understanding of the effect of electrolytes on the solubility of polymers, where a certain ion sequence, referred to as the Hofmeister or lyotropic series, is found.

From the experimental data shown in Figure 5 it is thus possible to observe that the swelling behavior of PVA membranes is quite different from that obtained for DNA-containing gels; it was also observed that the $Q_{\mathrm{ss}}$ of PVA is always lower than $Q_{\mathrm{ss}}$ of PVA-DNA gels. In the case of PVA gels the swelling is lowest; a slight increase of $Q_{\mathrm{ss}}$ occurs, in particular for [NaBr] $>0.01 \mathrm{M}$, suggesting a salting-in phenomena with a consequent increase of the swelling degree. For the DNA-containing gels it is possible to observe a collapse of the gel membranes until a $\mathrm{NaBr}$ concentration around $0.01 \mathrm{M}$, followed by a plateau for higher $\mathrm{NaBr}$ concentrations and a significant increase. These findings can thus be explained on the basis of simple electrostatic principles. At low ionic strength, the concentration of DNA charges and accompanying counterions within the gel exceed the concentration of $\mathrm{NaBr}$ in the external solution; a large ionswelling pressure causes the gel to expand, thereby lowering the concentration of counterions within the gel. As the external salt concentrations rises, the difference between the internal and external ion concentrations decreases and the gel collapses; the gel continues to deswell with rising external salt concentration until the mobile-ion concentrations within and surrounding the gel are approximately equal (here for about $0.01 \mathrm{M} \mathrm{NaBr}$ ). The subsequent relative independence of the gel swelling degree of the salt concentration and slight increase is referred to the same salting-in effect as observed for gels of PVA alone.

Two other interesting points deserve attention: (a) the shrinkage of $\mathrm{PVA}-\mathrm{DNA}-\mathrm{NaBr}$ is much more dramatic than that of the DNA-containing gel without $\mathrm{NaBr}$ and (b) the $Q_{\text {sw }}(\mathrm{PVA}-\mathrm{DNA}-$ $\mathrm{NaBr})>Q_{\text {sw }}(\mathrm{PVA}-\mathrm{DNA})$. Regarding point a, such a behavior clearly suggests that the presence of ds-DNA chains is in agreement with the previous results; in this case the presence of increasing concentrations of salt inside the polymer matrix will contribute to a further screening of ionic interactions, and consequently, the shrinkage is more efficient. ${ }^{27}$ In fact, this effect comes from the polyelectrolyte character of DNA; the counterions in the solution reduce the interpolymer electrostatic repulsion making DNA molecules more compact. The decrease of the cryogel crystallinity permits the DNA compaction. In the case of (b), it can be referred to the presence of $\mathrm{NaBr}$, directly resulting from gel membrane preparation, which contributes to a further increase of the swelling pressure; these data are also in agreement with the effect of $\mathrm{NaBr}$ on the cryogel crystallinity. The higher $\mathrm{NaBr}$ solution concentration is, the lower the PVA hydrogel crystallinity is, and as a consequence, the higher the swelling degree.

3.3. Transport Properties. The diffusivity $D$ of a solute in the hydrated polymer matrix was measured by the well-established method of desorption (elution) into water. This method is experimentally both more accurate and more convenient than absorption from aqueous solution. ${ }^{46} \mathrm{We}$ assumed that the swelling process occurs without significant alterations in the sample thickness during the whole process.

Desorption kinetics, and in particular the diffusion coefficient of the desorbed species, can be quantified using Fick's second law:

$$
\frac{\partial C}{\partial t}=\frac{\partial}{\partial x}\left(D \frac{\partial C}{\partial x}\right)
$$

where $D$ is the diffusion coefficient, $C$ is the concentration of the desorbed species, $x$ is the space coordinate, and $t$ is the time. For a planar sheet of thickness $l$, with uniform initial distribution and equal initial surface concentrations, Fick's second law leads to the following analytical equation:

(46) Papadokostaki, K. G. J. Appl. Polym. Sci. 2004, 92, 2468-2479. 


$$
\frac{C_{\mathrm{t}}}{C_{\mathrm{T}}}=1-\frac{8}{\pi^{2}} \sum_{n=0}^{\infty} \frac{1}{(2 n+1)^{2}} \exp \left[-(2 n+1)^{2} \pi^{2} \tau\right]
$$

where $C_{\mathrm{t}}$ and $C_{\mathrm{T}}$ are the concentrations of a desorbed species at time $t$ and at infinite time, respectively, and $\tau\left(=D t / l^{2}\right)$ is the dimensionless time.

For relatively small values of $\tau$, desorption first-half results $\left(C_{\mathrm{t}} / C_{\mathrm{T}}<0.6\right)$, eq 2 reduces to

$$
C_{\mathrm{t}} / C_{\mathrm{T}}=(4 / l)\left(t D_{\mathrm{ap}} / \pi\right)^{0.5}
$$

where $D_{\text {ap }}$ is the apparent diffusion coefficient for short times. DNA desorption from polymeric matrixes, in different media $\left(\mathrm{H}_{2} \mathrm{O}, \mathrm{NaBr}, \mathrm{NaCl}\right.$, and $\left.\mathrm{C}_{12} \mathrm{TAB}\right)$ shows a linear dependence from the square root of time according to eq 3 (Figure 6). The corresponding apparent diffusion coefficients, $D_{\text {ap }}$, are shown in Table 2 . These values were calculated by a least-squares minimum deviation fitting procedure (solid lines, Figure 6) of eq 3 to experimental data using MicroCal OriginPro software.

While these data refer to the short-time desorption effects, the picture has to be complemented with the long-time behavior. In Figure 7 are presented the complete desorption kinetics of DNA from the membranes and in Figure 8 the degree of retention of DNA in the membranes. The retention of DNA follows a simple electrostatic behavior considering the interaction between and the different cosolutes: a stronger interaction of a cation with DNA will decrease a desorption mainly driven by the entropy of the counterion distribution. The cationic surfactant ions, dodecyltrimethyl ammonium, will assembly at the DNA chains into multivalent surfactant self-assemblies associating strongly with DNA. This will both thermodynamically and kinetically decrease the tendency of DNA desorption. Simple salt will decrease the counterion driven DNA desorption by reducing differences in counterion concentration between gels and the surrounding solution; therefore, the desorption is less pronounced than with water. The fact that there is a (slightly) larger retention in the presence of electrolyte is also in line with simple electrostatic considerations; in the presence of electrolyte there is a smaller tendency to osmotic swelling. In all cases (except with surfactant) there is a markedly lower retention for membranes prepared with $\mathrm{NaBr}$; this is attributed to a release induced by the dissolution of electrolyte.

Turning to the short-time kinetics, an analysis of the data shown in Table 2 leads to the following observations: (a) the initial desorption, for all systems, shows good conformity to Fickian kinetics; (b) the apparent diffusion coefficients of DNA are 1-2 orders of magnitude lower than those found in agarose gels (taking into consideration the number of DNA base pairs, which is around 800$)^{47}$ and 4 orders of magnitude lower than the diffusion coefficients of DNA in free solution; ${ }^{48}$ (c) the presence of $\mathrm{NaBr}$ in the initial blend gives an increase of the DNA diffusion coefficient; (d) it is possible to control the desorption kinetics of DNA, from the gel, by changing the medium surrounding the gel.

The first two points show that the incorporation of DNA into PVA matrixes is a promising way for a controlled release of DNA since it only depends on the concentration gradient and the diffusion is quite different from that occurring in free solution. The last point deserves, however, further attention. In our experiments, the apparent diffusion coefficient of DNA describes the release of individual DNA molecules from gel matrixes.

(47) Pluen, A.; Netti, P. A.; Jain, R. K.; Berk, D. A. Biophys. J. 1999, 77, $542-552$.

(48) Stellwagen, E.; Stellwagen, N. C. Electrophoresis 2002, 23, 2794-2803.
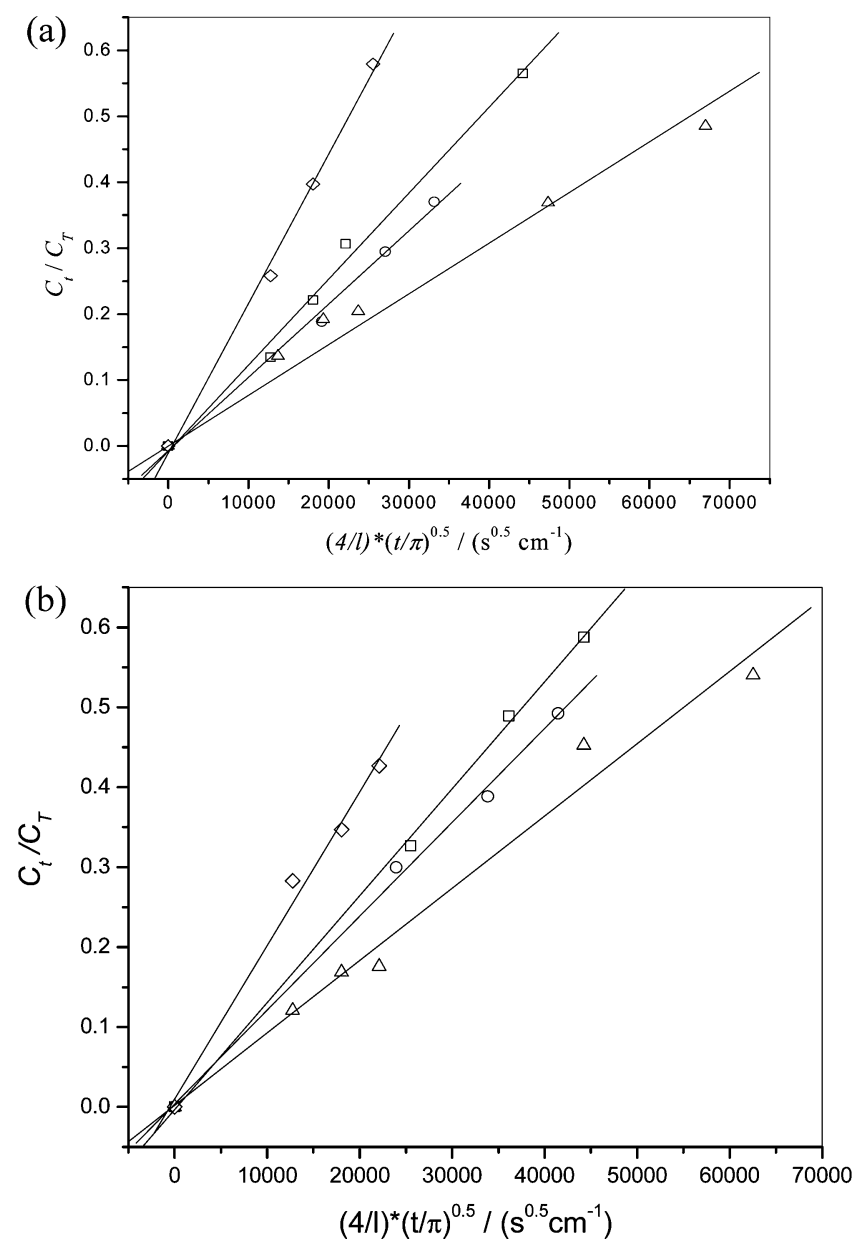

Figure 6. Short-time range $\left(C_{\mathrm{t}} / C_{\mathrm{T}}<0.6\right)$ desorption kinetics of DNA from PVA-DNA (a) and PVA-DNA- $\mathrm{NaBr}$ (b) gel matrixes, when immersed in different solutions: ( $\square$ ) $\mathrm{H}_{2} \mathrm{O}$, (O) $\mathrm{NaBr},(\triangle)$ $\mathrm{NaCl}$, and $(\diamond) \mathrm{C}_{12} \mathrm{TAB}$.

Table 2. Diffusion Coefficients, $D$, of DNA $(D)$, Calculated by Fitting Experimental Data, from DNA-Containing Gels Immersed in Different Aqueous Solutions, to Eq 3

\begin{tabular}{lcccc}
\hline & \multicolumn{4}{c}{$D_{\text {ap }}( \pm s) /\left(10^{-14} \mathrm{~m}^{2} \mathrm{~s}^{-1}\right)$} \\
\cline { 2 - 5 } & & & & $\mathrm{C}_{12} \mathrm{TAB}$, \\
$\mathrm{H}_{2} \mathrm{O}$ & $\mathrm{NaBr}, 0.1 \mathrm{M}$ & $\mathrm{NaCl}, 0.1 \mathrm{M}$ & $14 \mathrm{mM}$ \\
\hline PVA-DNA & $1.63(0.09)$ & $1.18(0.06)$ & $0.59(0.05)$ & $4.90(0.21)$ \\
PVA-DNA- & $1.77(0.04)$ & $1.40(0.05)$ & $0.83(0.06)$ & $3.90(0.24)$ \\
$\mathrm{NaBr}$ & & & &
\end{tabular}

Depending on the surrounding solution medium, $D_{\text {ap }}$ follows $D_{\text {ap }}($ water $)>D_{\text {ap }}(\mathrm{NaBr})>D_{\text {ap }}(\mathrm{NaCl})$. We attribute the retardation effect of the electrolytes to a stabilization of DNA in the gel state.

It is known that the sorption of salt by polyelectrolyte gels influences the electrostatic interactions between the network charges and the counterions; in the present case, the sorption of sodium chloride and bromide will affect electrostatic interactions between DNA and their counterions and, consequently, gel properties. The difference between the bromide and chloride co-ions is interesting. From the Hofmeister lyotropic salt series, ${ }^{49}$ $\mathrm{NaBr}$ has less influence on such screening process and, consequently, upon $\mathrm{NaBr}$ sorption, the amount of free (mobile) DNA is lower than with $\mathrm{NaCl}$ or, in other words, the free volume

(49) (a) Forsen, S.; Lindman, B. Chem. Br. 1978, 14, 29-35. (b) Lindman, B.; Forsen, S.; Forslind, E. J. Phys. Chem. 1968, 72, 2805. (c) Norne, J. E.; Hjalmarsson, S. G.; Lindman, B.; Zeppezauer, M. Biochemistry 1975, 14, 34013408 . 


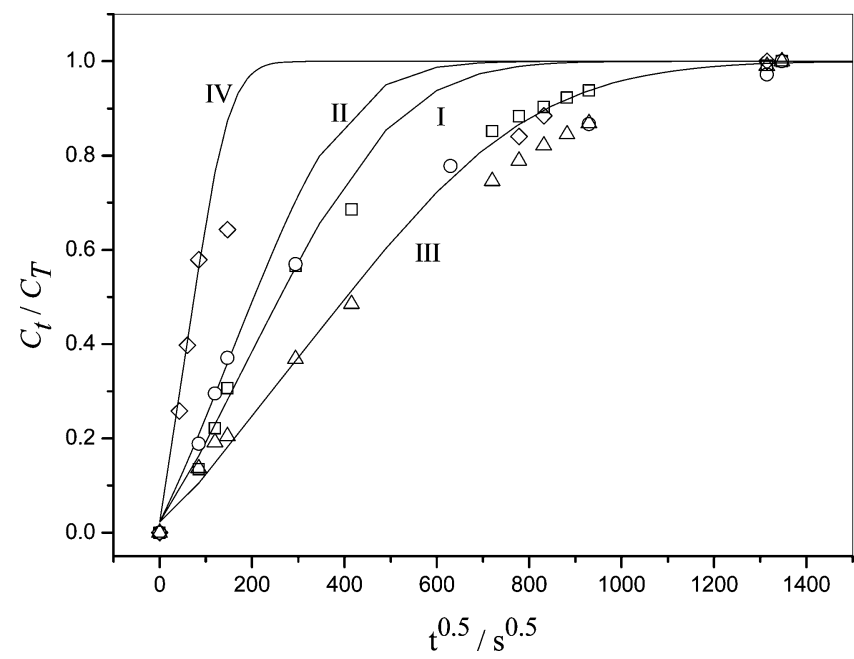

Figure 7. Desorption kinetics of DNA from PVA-DNA gel membranes in solutions of $\left(\square\right.$, I) $\mathrm{H}_{2} \mathrm{O}$, $(\mathrm{O}$, II $) \mathrm{NaBr},(\triangle$, III $) \mathrm{NaCl}$, and $(\diamond, \mathrm{IV}) \mathrm{C}_{12} \mathrm{TAB}$. Solid lines (I-IV) represent $C_{\mathrm{t}} / C_{\mathrm{T}}$ predicted by eq 2 and taking into account $D_{\text {ap }}$ shown in Table 2 .

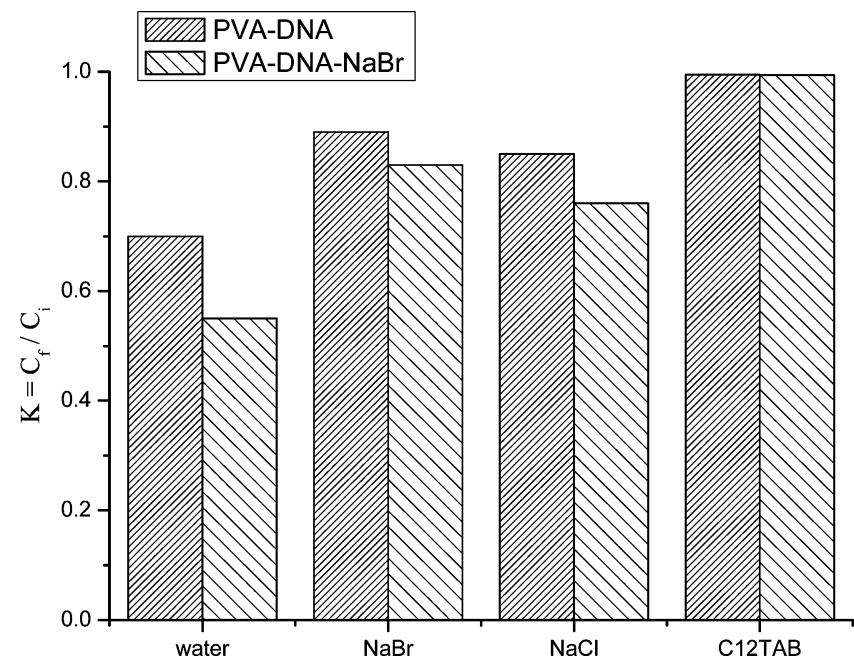

Figure 8. Effect of different solutions on the retention coefficients, $K$, of DNA inside the blend matrix.

to diffuse is lower, which is in agreement with the effect of $\mathrm{NaCl}$ and $\mathrm{NaBr}$ on PVA-based cryogels crystallinity, ${ }^{50}$ as pointed out above. In the case of $\mathrm{C}_{12} \mathrm{TAB}$ external solution, a different mechanism, although with similar conclusion, can explain the experimental results. DNA has a strong interaction with cationic surfactants. ${ }^{36}$ From these results a strong compaction of DNA and a hindered diffusion of DNA molecules is expected. In consequence we observe (see Figure 6) that only a very small fraction of DNA is released.

The mechanism of retention of DNA inside cryogel membranes is supported by an analysis of the complete elution curves as well as from the retention degree of DNA inside PVA gels (Figures 7 and 8 ). We can observe that at long time scales (when $C_{\mathrm{t}} / C_{\mathrm{T}}$ $>0.6$ and approaches 1) a negative deviation of experimental results, compared to the fitting line, is observed. Such a clearly non-Fickian behavior is indicative of some retarding effect on diffusion, ${ }^{51}$ i.e., such a deviation can indicate some association between DNA molecules and/or DNA and the polymeric matrix

(50) Iwaseya, M.; Katsuyama, N.; Yamaura, Y. J. Mater. Sci. 2006, 41, 19791982.

(51) Polishchuk, A. Ya.; Zaikov, G.E. Multicomponent Transport in Polymer Systems for Controlled Release; Gordon Breach Science Publishers: Amsterdam, 1997. or the cosolute. As can be seen from the retention coefficients of DNA inside of gel matrixes the amount of DNA that remains "encapsulated" inside the gel matrix is very high (from $50 \%$ to PVA-DNA $-\mathrm{NaBr}$ in water to around $98 \%$ in DNA-containing gels in $\mathrm{C}_{12} \mathrm{TAB}$ ).

The DNA retention of the gels depends on the interactions between the insertion (DNA) and the matrix (PVA) and also on the matrix morphology. From Figure 8, it can be seen that the retention coefficients of DNA follows the order $K\left(\mathrm{C}_{12} \mathrm{TAB}\right)>$ $K(\mathrm{NaBr})>K(\mathrm{NaCl})>K\left(\mathrm{H}_{2} \mathrm{O}\right)$. These data agree with the transport discussion as well as with the effect of salts and $\mathrm{C}_{12}$ $\mathrm{TAB}$ on the structure of DNA and gel. The DNA retention coefficient decreases when $\mathrm{NaBr}$ is present in the initial gel, for all the types of contact media, excepting the $\mathrm{C}_{12} \mathrm{TAB}$ solution. This behavior is in good agreement with the assumption given about that $\mathrm{NaBr}$ increases the amorphous part of PVA gel and, as a consequence, DNA would diffuse more easily through the more mobile parts of PVA molecules.

From all these data it is interesting to point out the efficiency of $\mathrm{C}_{12} \mathrm{TAB}$ to retain almost all initial DNA inside the PVA cryogel, even suggesting that a surfactant layer outside the membrane is produced.

\section{Conclusions}

Double-stranded DNA has been incorporated into PVA hydrogels obtained by a technique involving repeated freezingthawing in cycles. The obtained cryogels are free of potential toxic species like chemical cross-linkers and, as a consequence, could be used in pharmaceutical or medical applications.

The obtained cryogels show a good mechanical resistance and a white and opaque appearance due to a heterogeneous porous structure.

From FM and UV and FTIR spectroscopy we can state that encapsulated DNA molecules can be compacted or extended in the PVA matrix by tailoring the crystallinity degree of the PVA network. Two different forms of encapsulated DNA have been obtained: an extended one in more crystalline networks and a globular one in the more amorphous matrixes. Different bindings of base pairs have also been observed.

The crystallinity of the PVA cryogel could be tailored by the initial presence of $\mathrm{NaBr}$ in the matrix or by contacting the gels with solutions containing different salts. The effect of different salts $\left(\mathrm{NaBr}, \mathrm{NaCl}, \mathrm{C}_{12} \mathrm{TAB}\right)$ on the PVA crystallinity and, as a consequence, on its swelling capacity is in good agreement with the Hofmeister lyotropic salt series. Salting-in or salting-out effects that determine the compaction degree of the cryogel could be correlated with the DNA conformation and the diffusion coefficients from different cryogel blends.

The DNA retention coefficients in the PVA matrix have also been calculated. Their high values indicate strong interactions between PVA and DNA and were confirmed also by a nonFickian delivery of DNA.

The influence of DNA and $\mathrm{NaBr}$ on surface and bulk morphology has been studied by SEM and by porosimetry analysis. The correlation between PVA morphology and DNA conformation is in good agreement with the results of the other investigations.

All these results demonstrate an effective DNA encapsulation into the PVA cryogel matrix and indicate promising ways for tailored DNA delivery.

Acknowledgment. We are grateful for financial support from POCTI/FCT/FEDER and CIPSNAC. 